\title{
Reseña de la 41 Conferencia Internacional de la Asociación Internacional para la Psicología del Self Psicoanalítica (IAPSP), celebrada en Viena, 17 al 20 de Octubre de 2018: Viena-Kohut - La Psicología del Self en busca de la Creatividad en tiempos de crisis
}

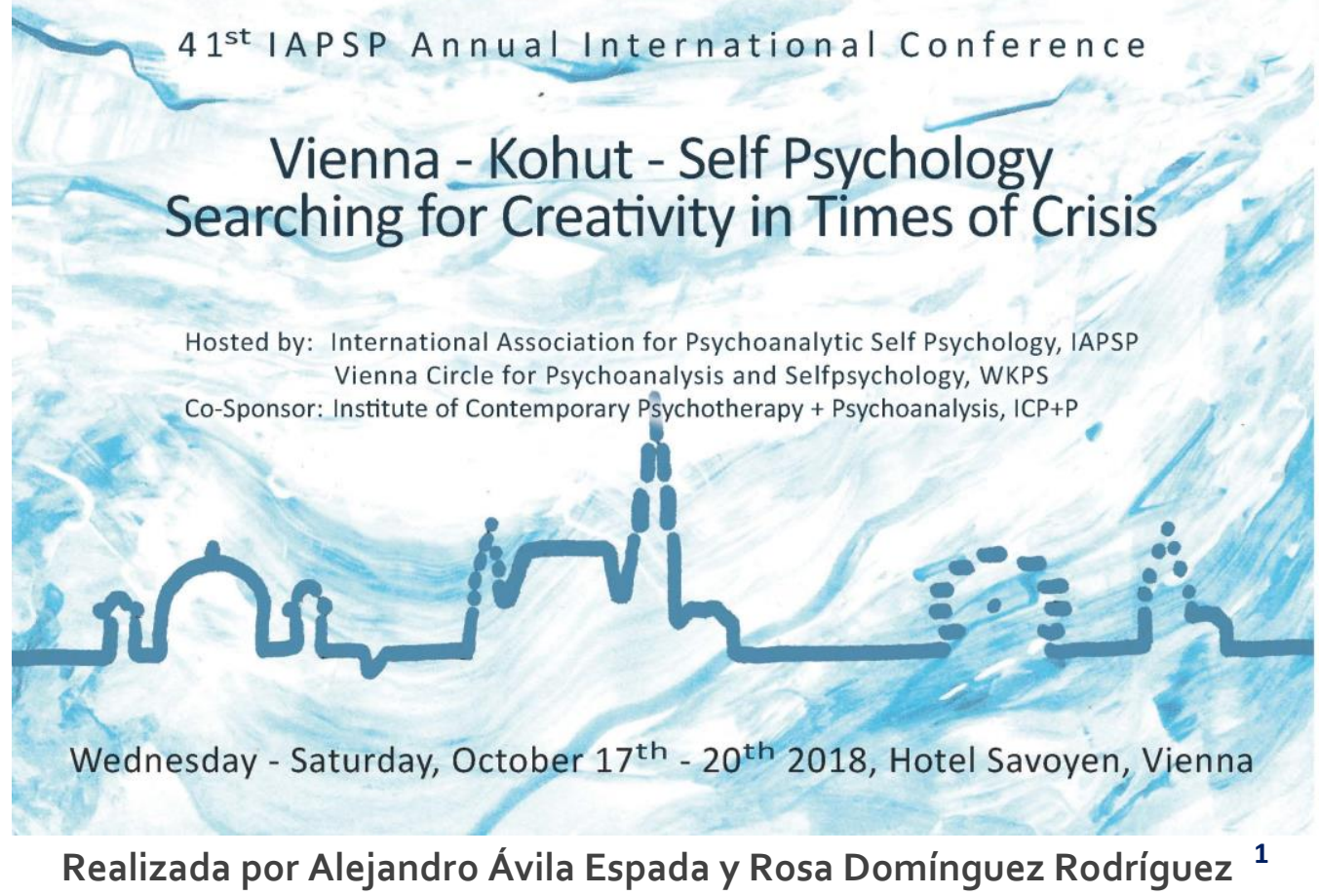

Viena nos convocó, ocho décadas después de la marcha de Heinz Kohut a Estados Unidos, y del exilio generalizado del Psicoanálisis ante el control de la prolífica sociedad vienesa en manos del nazismo. Viena, cuna del Psicoanálisis, y germen de muchas de las ideas que se plasmaron en los desarrollos posteriores del Psicoanálisis y la Psicoterapia Psicoanalítica, reunió este pasado mes de Octubre 2018 a una amplia representación de los principales contribuidores a la Psicología del Self Psicoanalítica desde todos los rincones del mundo. En lo que sigue haremos una reseña de lo compartido en Viena entre el 17 y 20 de Octubre de 2018.

\footnotetext{
${ }^{1}$ Ávila Espada, A. y Domínguez Rodríguez, R. (2018). Reseña de la 41 Conferencia Internacional de la Asociación Internacional para la Psicología del Self Psicoanalítica (IAPSP), celebrada en Viena, 17 al 20 de Octubre de 2018: Viena-Kohut - La Psicología del Self en busca de la Creatividad en tiempos de crisis. Clínica e Investigación Relacional, 12 (3): 624-628. [ISSN 1988-2939] [Recuperado de www.ceir.info ] DOI: 10.21110/19882939.2018.120316
} 
El congreso estuvo precedido por la sesión de talleres pre-conferencia, que estuvieron dedicados a los siguientes temas: nexo mente-cuerpo en la psicoterapia (Brothers y Sletvold); el uso del video en la supervisión (Milch, Schmitz-Huebsch y Mehner); las aplicaciones de la Psicología del Self en la reducción de la violencia escolar (Ketterer); a la recuperación de estados traumáticos y la visualización de opciones de futuro (Stern y WeiselBarth); a la intrusión de la política en los espacios de juego (Gotthold, Joelson, Lebersorger, Iko, Gossmann y Togashi); al tratamiento conjunto de madres con trastornios mentales graves y sus bebes (Hartmann); los temas más clínicos fueron completados con un curso introductorio a la Psicología del Self (Allen Siegel), los nexos entre Psicología del Self y La Teoría de las Relaciones de Objeto (Frank Summers) y el uso de la creatividad frente a la crisis (Joseph Lichtenberg y otros).

La sesión de apertura subrayó el nexo entre nuestra práctica y el compromiso social en cada realidad concreta, en la que las palabras del Presidente de IAPSP (Eldad Iddan) y la organizadora de la conferencia, representante del Grupo vienés (Andrea Harms) se unieron a las voces del coro infantil SUPERAR, una iniciativa de integración de niños procedentes de entornos con dificultades e inmigrantes a través de la música y la expresión artística.

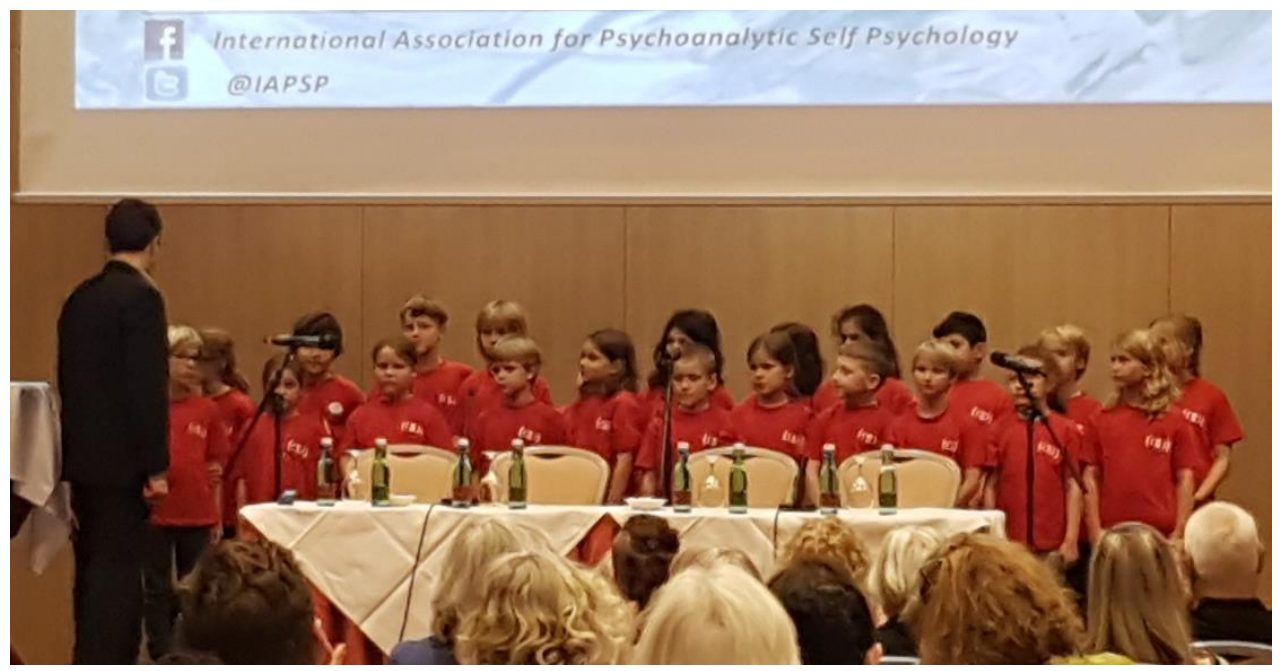

El primer plenario se dedicó a la Historia y su impacto en nuestras vidas, donde las condiciones traumáticas y las experiencias compartidas articulan lo vivido. Lo escuchamos en las palabras pronunciadas por Thomas Aichorn (hijo de August Aichorn, primer analista de Heinz Kohut), de Thomas Kohut (hijo de Heinz Kohut e historiador), con los brillantes aportes de Dagmar Herzog y Roger Frie. Una sesión dedicada a la "memoria histórica" del psicoanálisis, que nos atraviesa como personas y como clínicos. expresa. Este material es para uso científico y profesional exclusivamente y puede contener información clínica sensible. Los editores no se responsabilizan de los contenidos de los autores. Dirigir las consultas sobre derechos y autorizaciones a ceir@psicoterapiarelacional.es 


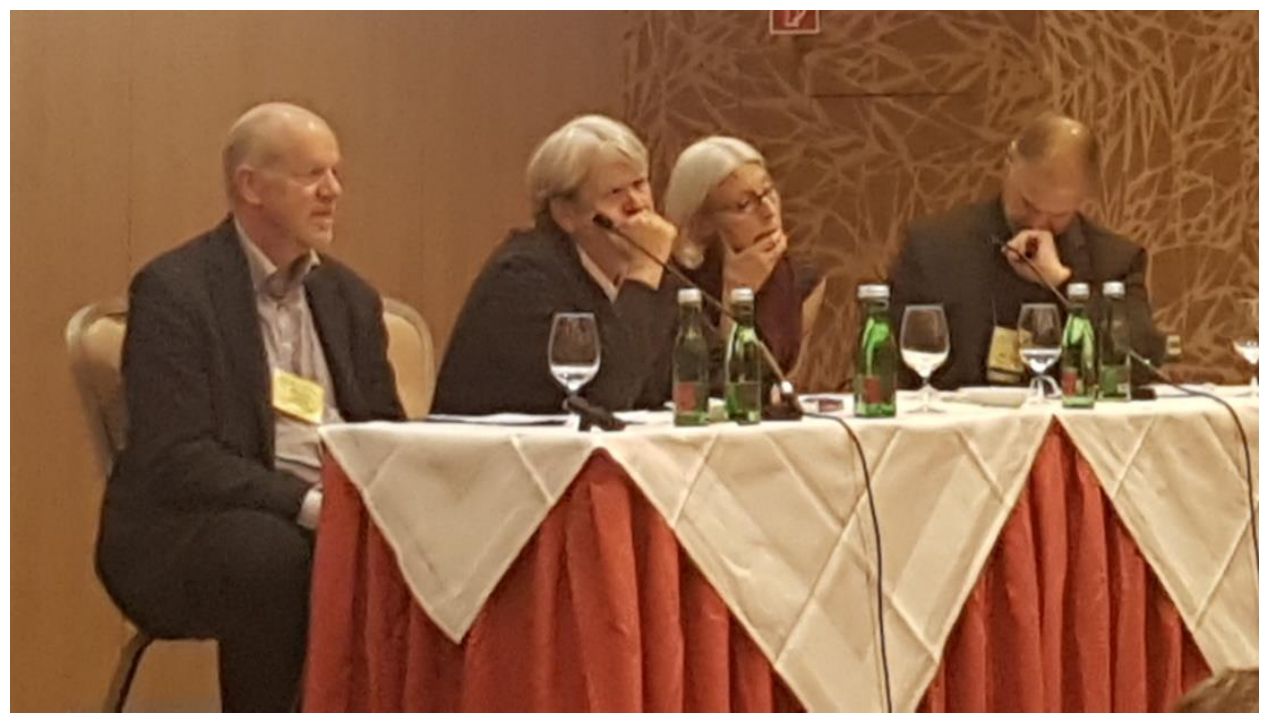

Tras el primer e inaugural plenario se celebró la recepción de bienvenida, en la que compartimos los encuentros sociales y personales con una excelente ocasión de intercambio y presentación de experiencias de los principales institutos psicoanalíticos que difunden la Psicología del Self contemporánea, en conexión con el pensamiento relacional.

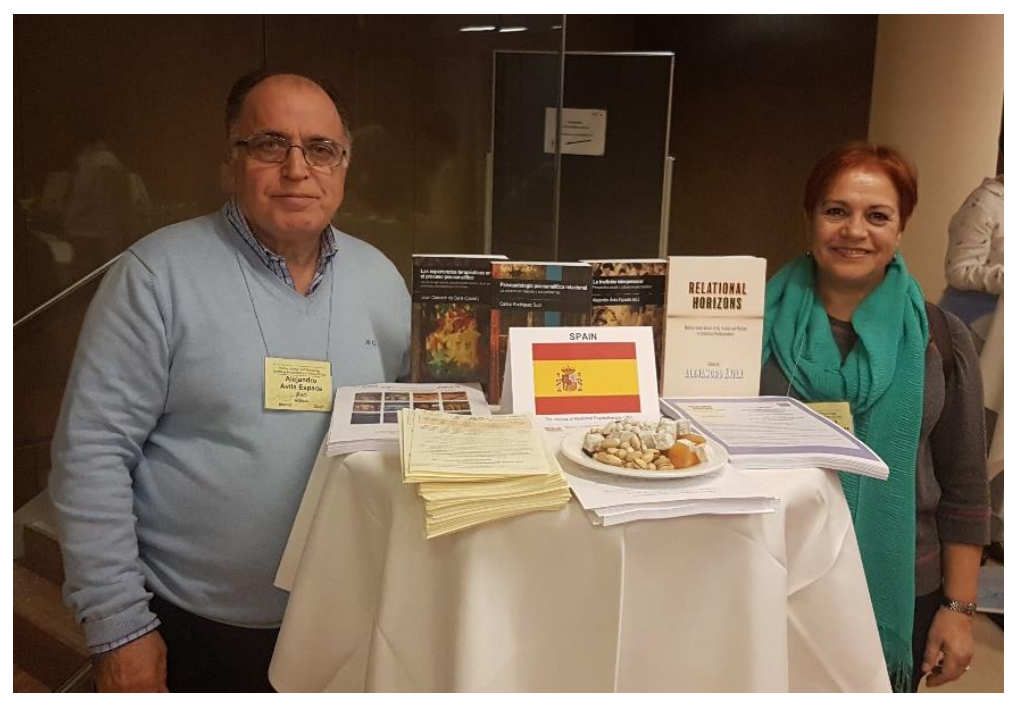

Nuestro Instituto de Psicoterapia Relacional, que es miembro institucional de la IAPSP estuvo representado en este acto por dos de sus miembros -los firmantes de esta reseña- $y$ desplegamos amplia información sobre nuestra historia, actividades, publicaciones, y fue ocasión de intercambiar con colegas e instituciones de todo el mundo (Japón, Italia, Turquía, Canadá, USA, China, Israel entre otros muchos).

Esa tarde la terminamos con un emotivo acto de recuerdo y despedida a Ernest Wolf, una de las figuras más destacadas de la Psicología del Self, que nos había dejado este mismo año.

\section{CeIR Vol. 12 (3) - Octubre 2018 ISSN 1988-2939-www.ceir.info}

@ ( Derechos reservados/Copyright de Clínica e investigación Relacional y los autores. Prohibida la reproducción total o parcial sin autorización expresa. Este material es para uso científico y profesional exclusivamente y puede contener información clínica sensible. Los editores no se responsabilizan de los contenidos de los autores. Dirigir las consultas sobre derechos y autorizaciones a ceir@psicoterapiarelacional.es 
Al día siguiente continuamos con el segundo plenario, esta vez dedicado a los nexos entre crisis y creatividad, en el que, con la coordinación de Donna Orange, Eldad Iddan, Chris Jaenicke y Amanda Kottler nos trajeron sus visiones desde Israel, USA y Sudáfrica, respectivamente. Como ya es costumbre y muy productiva, siete grupos paralelos de discusión permitieron desplegar interesantes debates a partir de sus propuestas y experiencias.

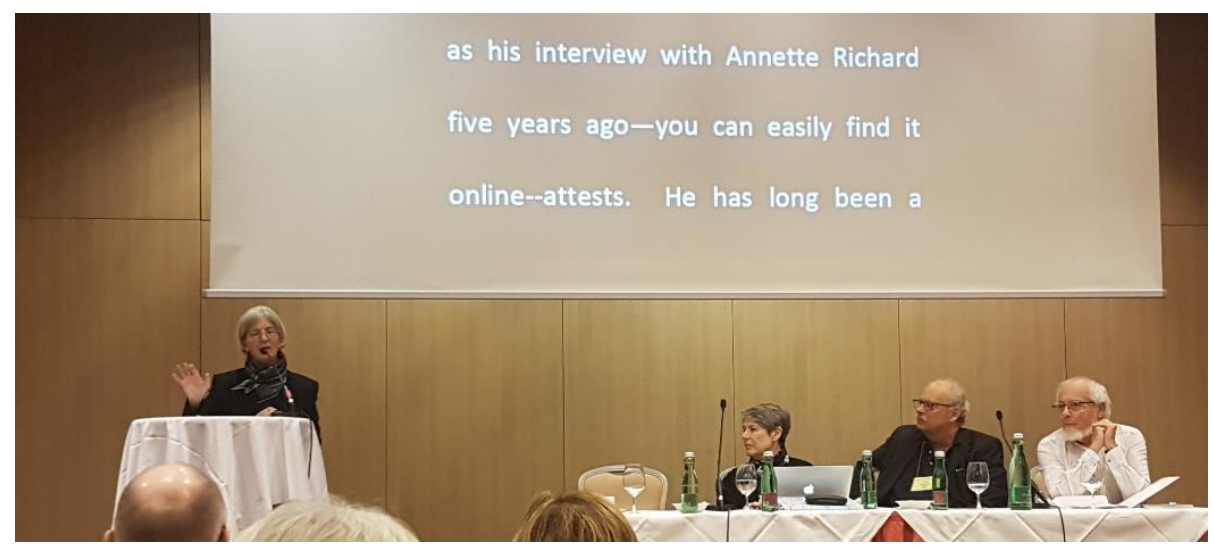

Las sesiones de presentación de trabajos, generalmente estructuradas como un debate entre dos o tres ponentes, incluyeron los temas de Psicoterapia de parejas (Shaddock y Faizi); Tratamiento de niños y adolescentes (Gat-Dubrov y Burtman), o la lectura de la historia como un proyecto ético psicoanalítico (Orange y Pulcini), de entre una sucesión de aportaciones de gran interés.

El tercer día disfrutamos de una brillante presentación clínica a cargo de Andrea Harms, de un caso en el que intervino en la adolescencia, y posteriormente en la etapa adulta, que contó con los comentarios de Heather Ferguson, Franz Resch y Shelley Doctors. Ese mismo dia Shelley Doctors impartió la Conferencia en Honor de Kohut, en la que revisó y puso en valor el concepto de Objeto del Self, como idea nuclear de las propuestas de Kohut. Su magnífica presentación que tendremos ocasión de leer en Psychoanalysis, Self and Context, y de la que ya nos había anticipado las ideas centrales en su Seminario en Madrid en Mayo 2018, recuperó la centralidad de este concepto para la psicoterapia contemporánea. 


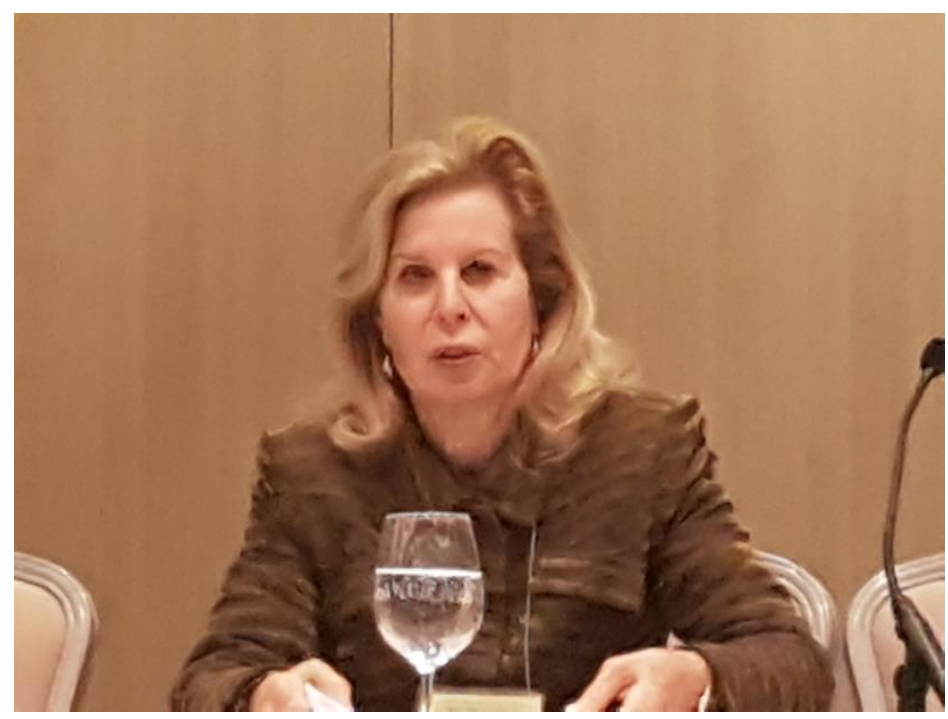

Esa noche, tras nuevas contribuciones y discusiones, nos encontramos en la Orangerie del Palacio de Schoenbrunn para compartir una exquisita cena y muy agradables momentos de encuentro con nuestros colegas, clases de vals a la vienesa, incluidas.

El plenario de cierre, de la mano de dos grandes maestros, Joseph Lichtenberg y Frank Lachmann, acompañados por el vienés Paulus Hochgatterer, nos acercó a los profundos nexos entre la biografía y la obra de los grandes creadores artísticos, en la pintura, y en la música. Con Josep Lichtenberg ya hemos tenido la oportunidad de trabajar en directo en Madrid, y con Frank Lachmann la tendremos el inicio del verano de 2020.

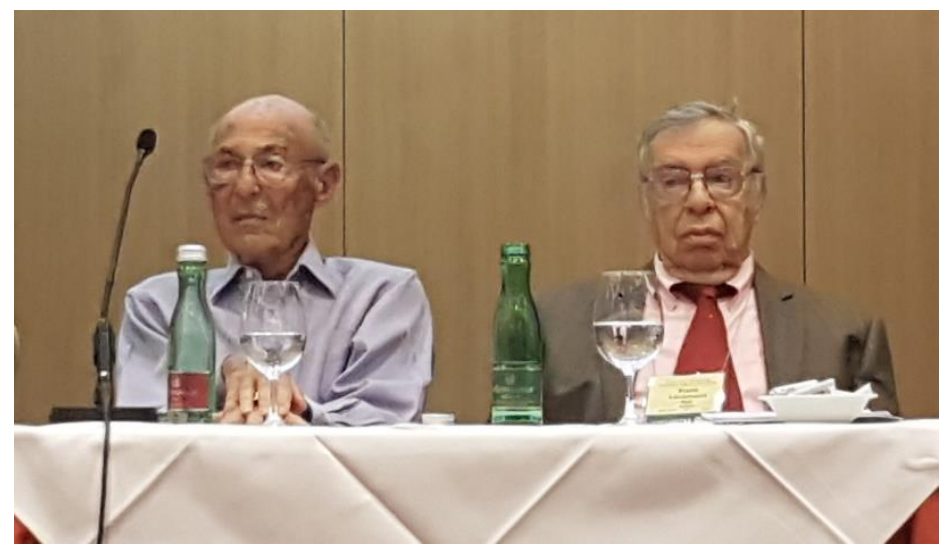

Y de Viena, qué decirles, toda ocasión para vivir sus entornos, cafés, conciertos, museos, jardines y parques será inestimable, y no debe perderse.

La 42 conferencia de la Psicología del Self Psicoanalítica se celebrará en Vancouver, Canadá, en Octubre de 2019, a la que les invitamos a asistir. 